\title{
What Provisions Do Orthopaedic Programs Make for Maternity, Paternity, and Adoption Leave?
}

\author{
Jennifer Weiss MD, David Teuscher MD
}

Published online: 13 April 2016

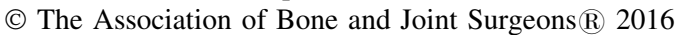

\begin{abstract}
Background The process of choosing medical specialty and residency programs is multifaceted. Today's generation of medical students may have an increased interest in work-life balance and time with their families. In considering this factor, medical students may be influenced by policy regarding maternity, paternity, and adoption leave during residency and fellowship training. Current policy among orthopaedic programs regarding maternity, paternity, and adoption leave is not well described. To understand the influence these policies may have on the choices that medical students make in choosing their specialty, the policies must first be better understood.

Questions/purposes (1) What proportion of orthopaedic programs have formal or unwritten policies regarding maternity, paternity, and adoptive leave? (2) What are the provisions for time away, allotment of time, and makeup options for trainees who take leave? (3) What proportion of orthopaedic programs report utilization of leave, and what
\end{abstract}

Each author certifies that he or she, or a member of his or her immediate family, has no funding or commercial associations (eg, consultancies, stock ownership, equity interest, patent/licensing arrangements, etc) that might pose a conflict of interest in connection with the submitted article.

All ICMJE Conflict of Interest Forms for authors and Clinical Orthopaedics and Related Research $\mathbb{R}$ editors and board members are on file with the publication and can be viewed on request.

This work was performed at the Southern California Permanente Medical Group, Los Angeles, CA, USA.

J. Weiss $(\square)$

Southern California Permanente Medical Group, 4760 Sunset

Boulevard, Los Angeles, CA 90077, USA

e-mail: jennifermweiss@yahoo.com

D. Teuscher

Beaumont Bone \& Joint Institute, Beaumont, TX, USA proportions of leave are for maternity, paternity, or adoptive reasons?

Methods Accredited programs in orthopaedic surgery were identified through the Council of Orthopedic Residency Directors within the American Orthopaedic Association. Current program directors of these accredited programs were surveyed. The survey was emailed to 144 program directors, of which 141 emails were delivered. Responses were received from 45 program directors, representing $31 \%$ of programs. The survey focused on maternity, paternity, and adoptive leave, and it consisted of questions designed to explore program policies (formal, unwritten, no policy, or in development), time considerations (amount allowed, allocation of time away, and makeup requirements), and utilization (trainees who took leave and type of leave used). Results Most respondents have maternity leave policy (formal: 36 of 45 [80\%]; unwritten: 17 of 45 [38\%]). Sixteen programs (16 of 45 [36\%]) reported having both a formal and an unwritten maternity leave policy. Less than half of the programs have paternity leave policy (formal: 22 of 45 [49\%]; unwritten: 19 of 45 [42\%]), and fewer programs have adoption leave policy (formal: eight of 45 [18\%]; unwritten: 11 of 45 [24\%]). For programs that have formal or unwritten policies, most programs allow 4 to 6 weeks off (26 of 43 [60\%]) with nearly half of programs allocating leave as paid time off ( 15 of 37 programs [41\%]) and nearly half of programs requiring makeup time (17 of 37 [46\%]). Many programs reported no utilization of leave by trainees (23 of $36[61 \%]$ ); many programs reported utilization by three or fewer residents (11 of 13 [85\%]); and among residents who took leave, maternity was the most common reason (maternity: 22 of 36 [61\%]; paternity: 11 of 36 [31\%]; adoption: three of 36 [8\%]).

Conclusions This study highlights the lack of uniformity among orthopaedic surgery residency and training 
programs regarding approach to maternity, paternity, and adoption leave. Discussion among program directors, perhaps facilitated by the Council of Orthopedic Residency Directors within the American Orthopaedic Association, to align the programs' policy in this arena may provide more transparent and uniform policy for trainees in orthopaedic surgery.

\section{Introduction}

Career choices among residents in 2015 are influenced by lifestyle and the ability to devote time to family [7, 8]. Maternity, paternity, and adoption leave factor into career choice $[7,8]$ and these policies vary by state and institution. The Accreditation Council for Continued Graduate Medical Education states in its Institutional Requirements, effective July 1, 2007, that "The Sponsoring Institution must provide written institutional policies on residents' vacation and other leaves of absence (with or without pay) to include parental and sick leave; these policies must comply with applicable laws" [1]. The US Department of Labor, in the Family Medical Leave Act (FMLA), states that, "The FMLA entitles eligible employees of covered employers to take unpaid, job-protected leave for specified family and medical reasons with continuation of group health insurance coverage under the same terms and conditions as if the employee had not taken leave. Eligible employees are entitled to 12 workweeks of leave in a 12month period for: the birth of a child and to care for the newborn child within one year of birth; the placement with the employee of a child for adoption or foster care and to care for the newly placed child within one year of placement" [9]. Specific policy regarding the leave of absence and the need to make up time by extending residency is addressed by the American Academy of Family Practice. Their policy states, "Absence from residency education, in excess of 1 month within the academic year (G-1, G-2 or G-3), must be made up before the resident advances to the next training level, and the time must be added to the projected date of completion of the required 36 months of training" [3]. The American Board of Orthopedic Surgery mandates that although individual programs may follow institutional policy regarding individual leave and vacation time, "one year of credit must include at least 46 weeks of full-time orthopaedic education." Allowance is also made for program directors to "retain a resident for as long as needed beyond the minimum required time to ensure the necessary degree of competence in orthopaedic surgery" [4].

It is not known whether orthopaedic residency programs have consistent and transparent policy regarding maternity, paternity, and adoption leave, as is outlined by the recommendations from the Accreditation Council for Continued Graduate Medical Education and FMLA. We therefore asked: (1) What proportion of orthopaedic programs have formal or unwritten policies regarding maternity, paternity, and adoption leave? (2) What are the provisions for time away, allotment of time, and makeup options for trainees who take leave? (3) What proportion of orthopaedic programs report utilization of leave, and what proportions of leave are for maternity, paternity, or adoptive reasons?

\section{Materials and Methods}

Accredited programs in orthopaedic surgery were identified through the Council of Orthopedic Residency Directors within the American Orthopaedic Association. Current program directors of these accredited programs were anonymously surveyed. The survey was emailed to 144 program directors, of which 141 emails were delivered. Reminder emails were sent 1 and 2 weeks after the initial survey. Anonymous responses were received from 45 program directors, representing $31 \%$ of programs.

The survey focused on maternity, paternity, and adoptive leave (for adoption of a child younger than 2 years of age), and it consisted of questions designed to explore program policies (formal, unwritten, no policy, or in development), time considerations (amount allowed, allocation of time away, and makeup requirements), and utilization (trainees who took leave and type of leave used) (Table 1).

Proportions and percentages are reported. Because response to each survey question was optional, each question had a different response rate. The response rate ranged from $29 \%$ (13 of 45) to $100 \%$ (45 of 45 ).

\section{Results}

Most programs have a maternity leave policy (formal: 36 of 45 [80\%]; unwritten: 17 of 45 [38\%]), less than half have a paternity leave policy (formal: 22 of 45 [49\%]; unwritten: 19 of 45 [42\%]), and fewer programs have an adoption leave policy (formal: eight of 45 [18\%]; unwritten: 11 of 45 [24\%]). Eight of 45 [18\%] programs have no formal policy, and 17 of 45 [38\%] have no unwritten policy. Some programs have both formal and unwritten maternity leave policy (16 of 45 [36\%]) and both formal and unwritten paternity leave policy (nine of 45 [20\%]). Fifteen programs have formal maternity leave policy and no formal paternity leave policy (15 of 45 [33\%]) and seven of these 15 programs have formal maternity leave 
policy with unwritten paternity leave policy (seven of 45 [16\%]). Most programs do not have policies in development (40 of 45 [89\%]), four of $45(9 \%)$ programs are considering policy development, and one of 45 (2\%) programs is in the policy development process. All five of the programs in policy development reported formal policy in place for maternity leave, two reported formal policy in place for maternity and paternity leave, and one reported formal policy in place for maternity, paternity, and adoption leave. Formal leave was more common for maternity and paternity leave, whereas unwritten policy was more common for adoption leave (Table 2).

For programs that have formal or unwritten policies, most programs allow 4 to 6 weeks off (4-6 weeks: 26 of 43

Table 1. Questionnaire

1. Does your residency/fellowship program have a current formal policy addressing leave for

Maternity

Paternity

Adoption

2. Does your residency/fellowship program have a policy addressing leave for maternity/paternity/parent of newly adopted child younger than age 2 years in writing?

In practice (but not formally in writing)

Under consideration (no current policy, but open to developing one)

No plans for such a policy; this has not been an issue for our program

3. If your program does have a policy, how much time away from work is allowed?

Less than 4 weeks

Between 4 and 6 weeks

More than 6 weeks

4. If time away does happen, is a resident/fellow able or required to make up that time after completion of the fifth year (or fellowship year)?

Able

Required

Neither required nor an option

5. If time away does happen, is it

Vacation

Sick time

Education/conference time

"Other" time away

6. Is there anything unique to your program about the way leave for maternity/paternity/adoption is handled?
[60\%]; > 6 weeks: eight of 43 [19\%]; < 4 weeks: four of 43 [9\%]), with nearly half of programs allocating leave as paid time off (paid time off: 15 of 37 [41\%]; vacation: 14 of 37 [38\%]; other protected time: 14 of 37 [38\%]; sick leave: 11 of 37 [30\%]; and educational/conference time: five of 37 [14\%]) and nearly half of programs requiring makeup time (required: 17 of 37 [46\%]; neither required nor an option: 14 of 37 [38\%]; as an option: six of 37 [16\%]).

Most programs reported no utilization of leave by trainees (23 of 36 [61\%]); most programs reported utilization by three or fewer residents (one to three residents: 11 of 13 [85\%]; four to six residents: two of 14 [15\%]); and among residents who took leave, maternity was the most common reason (maternity: 22 of 36 [61\%]; paternity: 11 of 36 [31\%]; adoption: three of 36 [8\%]). One program (one of $45[2 \%])$ responded that they are in a formal development process of a policy or practice for trainee time away for maternity/paternity/adoption leave. Four programs (four of 45 [9\%]) responded that they were considering or discussing such a policy. Forty programs (40 of 45 [89\%]) responded that they were not in discussion about such a policy. In response to question 3, "If your program does have a policy, how much time away from work is allowed?," program directors referenced the Accreditation Council for Graduate Medical Education and institutional policy as their guide. In response to the open-ended query regarding unique practices or approaches to maternity/paternity/adoption leave, responses varied among programs. The program directors referenced policy of the American Board of Orthopedic Surgery, Accreditation Council for Graduate Medical Education, and Residency Review Committee.

\section{Discussion}

This study was undertaken to gain insight into the uniformity and transparency of maternity, paternity, and adoption leave among orthopaedic training programs. This is an important issue, because accommodation of maternity/paternity and adoption leave is relevant for both male and female orthopaedic surgeons in striving for work-life balance, stress management, and burnout prevention [6]. The first aim is to report on the proportion of orthopaedic programs that have policy, either formal or informal. The

Table 2. Types of leave policy

\begin{tabular}{lllllllll}
\hline $\begin{array}{l}\text { No } \\
\text { leave }\end{array}$ & $\begin{array}{l}\text { Formal } \\
\text { maternity } \\
\text { leave }\end{array}$ & $\begin{array}{l}\text { Unwritten } \\
\text { maternity } \\
\text { leave }\end{array}$ & $\begin{array}{l}\text { Formal } \\
\text { paternity } \\
\text { leave }\end{array}$ & $\begin{array}{l}\text { Unwritten } \\
\text { paternity } \\
\text { leave }\end{array}$ & $\begin{array}{l}\text { Formal } \\
\text { adoption } \\
\text { leave }\end{array}$ & $\begin{array}{l}\text { Unwritten } \\
\text { adoption } \\
\text { leave }\end{array}$ & $\begin{array}{l}\text { Formal and } \\
\text { unwritten } \\
\text { maternity leave }\end{array}$ & $\begin{array}{l}\text { Formal and } \\
\text { unwritten } \\
\text { paternity leave }\end{array}$ \\
\hline 5 & 36 & 17 & 22 & 19 & 8 & 11 & 15 & $\begin{array}{l}\text { Formal and } \\
\text { unwritten } \\
\text { adoption leave }\end{array}$ \\
\hline
\end{tabular}


second aim is to describe the provisions for time away and strategy to provide this time. Lastly, the third aim is to report the utilization of time away for maternity, paternity, and adoption leave.

The largest limitation to this study is that of survey response bias. Because the surveys were intentionally administered in an anonymous fashion, there are no data to compare the responders from the nonresponders in important ways such as the size of program, number and percentage of women faculty and trainees, geography, and urban versus rural location of the program. There may be a bias in the responders in terms of their interest in the issues surrounding maternity, paternity, and adoption leave. Another limitation is that the institution's graduate medical education policy, the Accreditation Council for Graduate Medical Education, the Residency Review Committee, and state employment restrictions may conflict with or supersede what program directors may think.

\section{Maternity, Paternity, and Adoption Leave}

Although most responding orthopaedic programs have a maternity leave policy, fewer programs have defined paternity and adoption policies. Maternity leave policy has taken precedent over paternity and adoption leave policy, perhaps as a result of priorities generated by residents as reflected in 2007 findings by Sanfey et al. [8]. They report that in deciding whether to apply for a surgical residency, the decision to have a family was a more significant influence for women than men [2]. These issues have been shown to matter to both women and men, however, as shown in 2006 by Saalwachter et al. [7]. This work shows that more than one in four medical students, both male and female, agreed to increased interest in surgical careers if part-time training were an option, trading less hours per week for more years in training [3].

\section{How Leave Time Is Managed by Programs}

There is wide variation in time-off provisions and how leave time is designated among orthopaedic training programs. More uniformity is needed for training requirements when leave is taken. In 2006, Saalwachter et al. [7] conducted a study of over 4000 surgeons, surgical fellows, surgical residents, and medical students. Orthopaedics is certainly not unique in lack of uniformity in this arena, because general surgery training programs have also been shown to have variation in policy on maternity and paternity leave [7]. The relevant governing bodies in this arena leave room for institutional leeway. However, the stipulation by the American Board of Orthopedic Surgery
(ABOS) that may have the most influence over this matter is the requirement that each year of orthopaedic training must include at least 46 weeks of orthopaedic education. There are therefore not more than 6 weeks of time that can be allotted to leave within a year to remain compliant with the ABOS. This is in contrast to the FMLA, which entitles the trainee to 12 weeks of leave. The program directors and institutions thus have conflicting policy to reconcile, which may account for some of the inconsistency in the reported approaches to these policies.

\section{Reporting on Utilization of Leave}

Most programs reported no utilization of maternity/paternity/adoption leave. Provision of maternity leave has been shown to not necessarily correlate with utilization of maternity leave, which may corroborated in this study [2]. Because longer maternity leave may correlate with improvement in maternal mental health, it is in the interest of the orthopaedic community to weigh this benefit against the downside of taking time away from training [5].

Despite answering some important questions regarding maternity, paternity, and adoption leave, there are gaps that remain. This study has identified disparity in policy among orthopaedic programs and suggests that maternity, paternity, and adoption leave is infrequently taken by orthopaedic trainees. The interest in the benefit of leave for new mothers, fathers, and adoptive parents may broaden as interest in decreased burnout and improved resilience in the orthopaedic profession gains traction. This study has not addressed the correlation between quality of training and the ability to take extended leave nor has it determined whether consistency and transparency of policy in leave would attract more applicants to orthopaedic surgery.

In conclusion, maternity leave policy is more consistently present than paternity and adoption leave policy. When time away is taken for new parents, it is usually between 4 and 6 weeks. Utilization of all of these leaves is low. Consideration should be given to alignment of orthopaedic training program policy in the arena of maternity, paternity, and adoption leave. In addition, the policy surrounding and the use of paternity and adoption leave should be as transparent and available as maternity leave. This discussion may best be facilitated by the Council of Orthopedic Residency Directors within the American Orthopaedic Association. Once changes are implemented, survey of residents who use leave and comparison of their success in residency will be possible.

Acknowledgments We thank the American Orthopedic Association, specifically Myria A. Stanley, Education Manager, for facilitating the survey of the Council of Orthopaedic Residency Directors. 


\section{References}

1. Accreditation Council for Graduate Medical Education. ACGME Institutional Requirements Effective July 1, 2007. Available at: www.ACGME.org. Accessed February 22, 2016.

2. Aitken Z, Garrett CC, Hewitt B, Keogh L, Hocking JS, Kavanagh AM. The maternal health outcomes of paid maternity leave: a systematic review. Soc Sci Med. 2015;130:32-41.

3. American Academy of Family Practice. Parental Leave During Residency Training. Available at: http://www.aafp.org/about/ policies/all/parental-leave.html. Accessed February 22, 2016.

4. American Board of Orthopedic Surgery. Available at: http://www. abos.org. Accessed February 22, 2016.
5. Chatterji P, Markowitz S. Family leave after childbirth and the mental health of new mothers. J Ment Health Policy Econ. 2012;15:61-76.

6. Mayer KL, Ho HS, Goodnight JE Jr. Childbearing and child care in surgery. Arch Surg. 2001;136:649-655.

7. Saalwachter AR, Freischlag JA, Sawyer RG, Sanfey HA. Part-time training in general surgery: results of a web-based survey. Arch Surg. 2006;141:977-982.

8. Sanfey HA, Saalwachter-Schulman AR, Nyhof-Young JM, Eidelson B, Mann BD. Influences on medical student career choice: gender or generation? Arch Surg. 2006;141:1086-1094; discussion 1094.

9. US Department of Labor. Family Medical Leave Act. Available at: http://www.dol.gov/whd/fmla/. Accessed February 22, 2016. 